Judith Nyfeler

Die Fabrikation von Kreativität 
Fashion is a form of ugliness so intolerable that we have to alter it every six months. (Oscar Wilde)

Judith Nyfeler promovierte 2018 an der Universität Luzern. Sie lehrt und forscht im Bereich Organisations- und Wirtschaftssoziologie. Ihre Themenschwerpunkte sind Kreativität, Sprache und Mode. 
Judith Nyfeler

\section{Die Fabrikation von Kreativität}

Organisation und Kommunikation in der Mode 
Die vorliegende Arbeit wurde 2018 vom Soziologischen Seminar der Kulturund Sozialwissenschaftlichen Fakultät der Universität Luzern als Dissertation angenommen.

Gutachter*in: Prof. Dr. Raimund Hasse und Prof. Dr. Sophie Mützel

Publiziert mit Unterstützung des Schweizerischen Nationalfonds zur Förderung der wissenschaftlichen Forschung

\section{Bibliografische Information der Deutschen Nationalbibliothek}

Die Deutsche Nationalbibliothek verzeichnet diese Publikation in der Deutschen Nationalbibliografie; detaillierte bibliografische Daten sind im Internet über http://dnb.d-nb.de abrufbar.

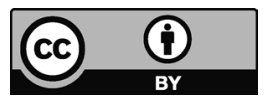

Dieses Werk ist lizenziert unter der Creative Commons Attribution 4.0 Lizenz (BY). Diese Lizenz erlaubt unter Voraussetzung der Namensnennung des Urhebers die Bearbeitung, Vervielfältigung und Verbreitung des Materials in jedem Format oder Medium für beliebige Zwecke, auch kommerziell. (Lizenztext:

https://creativecommons.org/licenses/by/4.o/deed.de)

Die Bedingungen der Creative-Commons-Lizenz gelten nur für Originalmaterial. Die Wiederverwendung von Material aus anderen Quellen (gekennzeichnet mit Quellenangabe) wie z.B. Schaubilder, Abbildungen, Fotos und Textauszüge erfordert ggf. weitere Nutzungsgenehmigungen durch den jeweiligen Rechteinhaber.

Erschienen 2019 im transcript Verlag, Bielefeld

(C) Judith Nyfeler

Umschlaggestaltung: Maria Arndt, Bielefeld

Korrektorat: Dr. Wolfgang Delseit, Köln

Satz: Isabel Lina Christen, Basel

Druck: Majuskel Medienproduktion GmbH, Wetzlar

Print-ISBN 978-3-8376-4992-5

PDF-ISBN 978-3-8394-4992-9

https://doi.org/10.14361/9783839449929

Gedruckt auf alterungsbeständigem Papier mit chlorfrei gebleichtem Zellstoff. Besuchen Sie uns im Internet: https://www.transcript-verlag.de

Unsere aktuelle Vorschau finden Sie unter

www.transcript-verlag.de/vorschau-download 